Marquette University

e-Publications@Marquette

Biomedical Engineering Faculty Research and

Publications

Biomedical Engineering, Department of

$1-2017$

\title{
Diffusion Tensor Imaging Correlates with Short-Term Myelopathy Outcome in Patients with Cervical Spondylotic Myelopathy
}

\author{
Aditya Vedantam \\ Baylor College of Medicine \\ Avinash Rao \\ University of Wisconsin School of Medicine and Public Health, Madison \\ Shekar N. Kurpad \\ Medical College of Wisconsin \\ Michael B. Jirjis \\ Marquette University \\ Gerald Eckardt \\ Medical College of Wisconsin
}

See next page for additional authors

Follow this and additional works at: https://epublications.marquette.edu/bioengin_fac

Part of the Biomedical Engineering and Bioengineering Commons

\section{Recommended Citation}

Vedantam, Aditya; Rao, Avinash; Kurpad, Shekar N.; Jirjis, Michael B.; Eckardt, Gerald; Schmit, Brian D.; and Wang, Marjorie C., "Diffusion Tensor Imaging Correlates with Short-Term Myelopathy Outcome in Patients with Cervical Spondylotic Myelopathy" (2017). Biomedical Engineering Faculty Research and Publications. 467.

https://epublications.marquette.edu/bioengin_fac/467 


\section{Authors}

Aditya Vedantam, Avinash Rao, Shekar N. Kurpad, Michael B. Jirjis, Gerald Eckardt, Brian D. Schmit, and Marjorie C. Wang

This article is available at e-Publications@Marquette: https://epublications.marquette.edu/bioengin_fac/467 


\title{
Diffusion Tensor Imaging Correlates with Short-Term Myelopathy Outcome in Patients with Cervical Spondylotic Myelopathy
}

\author{
Aditya Vedantam \\ Department of Neurosurgery, Baylor College of Medicine, \\ Houston, TX \\ Avinash Rao \\ University of Wisconsin School of Medicine and Public Health, \\ Madison, WI \\ Shekar N. Kurpad \\ Department of Neurosurgery, Medical College of Wisconsin, \\ Milwaukee, WI \\ Michael B. Jirjis \\ Department of Biomedical Engineering, Marquette University, \\ Milwaukee, WI \\ Gerald Echardt \\ Department of Neurosurgery, Medical College of Wisconsin, \\ Milwaukee, WI
}




\author{
Brian D. Schmit \\ Department of Biomedical Engineering, Marquette University, \\ Milwaukee, WI \\ Marjorie C. Wang \\ University of Wisconsin School of Medicine and Public Health, \\ Madison, WI
}

Objective: To determine if spinal cord diffusion tensor imaging indexes correlate with short-term clinical outcome in patients undergoing elective cervical spine surgery for cervical spondylotic myelopathy (CSM).

Methods: A prospective consecutive cohort study was performed in patients undergoing elective cervical spine surgery for CSM. After obtaining informed consent, patients with CSM underwent preoperative T2-weighted magnetic resonance imaging and diffusion tensor imaging of the cervical spine.

Fractional anisotropy (FA) values at the level of maximum cord compression and at the noncompressed C1-2 level were calculated on axial images. We recorded the modified Japanese Orthopaedic Association (mJOA) scale, Neck Disability Index, and Short Form-36 physical functioning subscale scores for all patients preoperatively and 3 months postoperatively. Statistical analysis was performed to identify correlations between FA and clinical outcome scores.

Results: The study included 27 patients (mean age 54.5 years $\pm 1.9,12$ men). The mean postoperative changes in mJOA scale, Neck Disability Index, and Short Form-36 physical functioning subscale scores were $0.9 \pm 0.3,-6.0$ \pm 1.9 , and $3.4 \pm 1.9$. The mean FA at the level of maximum compression was significantly lower than the mean FA at the C1-2 level (0.5 vs. $0.55, P=$ $0.01)$. FA was significantly correlated with change in mJOA scale score (Pearson $r=-0.42, P=0.02$ ). FA was significantly correlated with the preoperative mJOA scale score (Pearson $r=0.65, P<0.001$ ).

Conclusions: Preoperative FA at the level of maximum cord compression significantly correlates with the 3-month change in mJOA scale score among patients with CSM. FA was also significantly associated with preoperative mJOA scale score and is a potential biomarker for spinal cord dysfunction in CSM.

Key words: Cervical spine, Diffusion tensor, Diffusion tensor imaging, Fractional anisotropy, Magnetic resonance imaging, Myelopathy Spondylosis

\title{
Abbreviations and Acronyms
}

- CSM, Cervical spondylotic myelopathy;

- DTI, Diffusion tensor imaging;

- FA, Fractional anisotropy;

- $\mathrm{mJOA}$, modified Japanese Orthopedic Association;

- MRI, Magnetic resonance imaging;

- NDI, Neck Disability Index;

- SF-36, Short Form-36

World Neurosurgery, Vol 97 (January 2017): pg. 489-494. DOI. This article is (C) Elsevier B.V. and permission has been granted for this version to appear in e-Publications@Marquette. Elsevier B.V. does not grant permission for this article to be further copied/distributed or hosted elsewhere without the express permission from Elsevier B.V. 
NOT THE PUBLISHED VERSION; this is the author's final, peer-reviewed manuscript. The published version may be accessed by following the link in the citation at the bottom of the page.

\section{Introduction}

The current imaging standard to evaluate patients with cervical spondylotic myelopathy (CSM) is T1-weighted and T2-weighted magnetic resonance imaging (MRI). Although some studies suggest that preoperative T1-weighted or T2-weighted abnormalities are associated with patient outcome after surgery for these conditions, the literature is inconsistent, and outcome prediction remains a challenge. $\underline{1}, \underline{2}, \underline{3}, 4, \underline{5}, \underline{6}$ and $\underline{z}$ Furthermore, some patients show clinical signs of myelopathy in the absence of intramedullary MRI T1 or T2 signal abnormalities. The limitations with T1-weighted and T2-weighted MRI point to the need for more specific and sensitive imaging techniques to evaluate patients with CSM.

Diffusion tensor imaging (DTI) quantifies the diffusion of water molecules within tissues, enabling characterization of microstructural alterations in the spinal cord. In patients with spinal cord dysfunction, changes in DTI indexes have been reported in regions of the cord that appear normal on T2-weighted MRI. $\underline{8}$ and 9 Fractional anisotropy (FA), which is a measure of directional asymmetry of the diffusion of water molecules, is commonly used to evaluate spinal cord architecture. $\stackrel{10}{\mathrm{FA}}$ has been used to evaluate cervical cord damage in patients with CSM르, $9,11, \underline{12}, \underline{13}$ and 14 and shows marked changes at the level of maximum cord compression. Although some authors have demonstrated a correlation between FA and preoperative clinical status, $\underline{11}$ and $\underline{15}$ there is limited literature on the association between DTI indexes and clinical outcome after surgery for CSM. $\underline{\underline{15}}$

The purpose of this study was to determine if DTI indexes correlate with short-term clinical outcome in patients undergoing elective cervical spine surgery for CSM. We hypothesized that FA was associated with changes in clinical measures of the symptoms of myelopathy (using the modified Japanese Orthopaedic Association [mJOA] scale) before surgery and at follow-up 3 months after surgery. We also evaluated correlations between FA and preoperative clinical mJOA scale scores.

World Neurosurgery, Vol 97 (January 2017): pg. 489-494. DOI. This article is (C) Elsevier B.V. and permission has been granted for this version to appear in e-Publications@Marquette. Elsevier B.V. does not grant permission for this article to be further copied/distributed or hosted elsewhere without the express permission from Elsevier B.V. 
NOT THE PUBLISHED VERSION; this is the author's final, peer-reviewed manuscript. The published version may be accessed by following the link in the citation at the bottom of the page.

\section{Materials and Methods}

\section{Patient Characteristics and Study Design}

We performed a prospective, consecutive cohort study of DTI and clinical outcome in patients undergoing elective cervical spine surgery for CSM. Patients were enrolled consecutively from March 2010 through December 2012. The presence of myelopathy was defined by the treating surgeon and included $\geq 1$ of the following symptoms: hyperreflexia, clonus, clumsy hands, Hoffmann or Babinski reflexes, bowel/bladder dysfunction, and gait dysfunction. Exclusion criteria were prior cervical spine surgery, a nondegenerative diagnosis, comorbid diseases such as multiple sclerosis or rheumatoid arthritis, and central cord syndrome.

All patients provided informed consent before enrolling in the study, and a cash incentive was provided for participation in this study. Demographic, surgical, imaging, and outcomes data were collected for all patients. Before surgery, all patients were scored for myelopathy using the mJOA scale. All patients also filled out the Neck Disability Index (NDI) and Short Form-36 (SF-36) health survey. Patients underwent T2-weighted MRI and DTI of the cervical spine before surgery. Surgeries were performed at a single academic center by 5 board-certified, fellowship-trained spinal neurosurgeons. The mJOA scale, NDI, and SF-36 surveys were obtained at 3-month followup. This study was approved by our institutional review board.

\section{Clinical Outcome}

Clinical outcome measures were calculated as the change in mJOA scale, NDI, and SF-36 physical functioning subscale scores at 3 months after surgery compared with the preoperative scores (3-month postoperative score minus the preoperative score). Primary outcome was defined as the change in mJOA scale score, whereas secondary outcomes were defined as the changes in NDI and the SF-36 physical functioning subscale score.

World Neurosurgery, Vol 97 (January 2017): pg. 489-494. DOI. This article is (C) Elsevier B.V. and permission has been granted for this version to appear in e-Publications@Marquette. Elsevier B.V. does not grant permission for this article to be further copied/distributed or hosted elsewhere without the express permission from Elsevier B.V. 
NOT THE PUBLISHED VERSION; this is the author's final, peer-reviewed manuscript. The published version may be accessed by following the link in the citation at the bottom of the page.

\section{Imaging}

\section{T2-Weighted MRI}

A 1.5T MRI scanner (Signa Excite; GE Healthcare, Milwaukee, Wisconsin, USA) with a CTL spine coil (GE Healthcare) was used to obtain images of the cervical spinal cord in all subjects. T2-weighted sagittal MRI was used to identify the level of maximum cord compression in patients with CSM. The presence of intramedullary T2weighted hyperintensities at the level of maximum compression was noted on sagittal MRI in each patient with CSM.

\section{$D T I$}

Diffusion-weighted images of the cervical spine (C1-T1) were acquired using a standard single-shot, twice-refocused, spin-echo, echo planar image pulse sequence. Axial image slices $3 \mathrm{~mm} \times 3 \mathrm{~mm}$ with 3-mm gap between slices were acquired in 15 directions and collected with $a b=600$ second $/ \mathrm{mm}^{2}$ and a single T2-weighted $(b=0$ second $/ \mathrm{mm}^{2}$ ) image. Diffusion-weighted images were obtained with repetition time/echo time $=5000 \mathrm{~ms} / 98.2 \mathrm{~ms}$, field of view $=19 \mathrm{~cm}^{2}$, number of excitations $=2$, and matrix size of $128 \times 128$. Sagittal T2weighted images were obtained with repetition time/echo time $=4000$ $\mathrm{ms} / 102 \mathrm{~ms}$, field of view $=20 \mathrm{~cm}^{2}$, and matrix size of $384 \times 224$.

\section{Image Processing}

Geometric distortions associated with susceptibility variations, eddy currents, and subject motion were corrected using a Fourier transform-based affine registration of the diffusion-weighted images to the T2-weighted images. Analysis of Functional NeuroImages processing suite (available at http://afni.nimh.nih.gov/afni) was used to process the, and the eigenvalues of the diffusion tensor for each voxel were identified. A nonlinear constrained tensor-fitting algorithm was used to compute DTI metrics, and a gradient descent method was used for optimization. We calculated the FA (defined by Pierpaoli and Basser ${ }^{16}$ ) using the measured eigenvalues.

World Neurosurgery, Vol 97 (January 2017): pg. 489-494. DOI. This article is (C) Elsevier B.V. and permission has been granted for this version to appear in e-Publications@Marquette. Elsevier B.V. does not grant permission for this article to be further copied/distributed or hosted elsewhere without the express permission from Elsevier B.V. 
NOT THE PUBLISHED VERSION; this is the author's final, peer-reviewed manuscript. The published version may be accessed by following the link in the citation at the bottom of the page.

\section{Regions of Interest}

Axial FA maps at the level of maximum compression and at the noncompressed C1-2 level were selected for analysis (Figure 1). Custom software written in MATLAB (MathWorks, Natick, Massachusetts, USA) was used to draw regions of interest on FA maps. Regions of interest were drawn manually to include the whole cord, excluding at least 2 voxels at the edge of the cord, minimizing the risk of partial volume effects caused by cerebrospinal fluid.

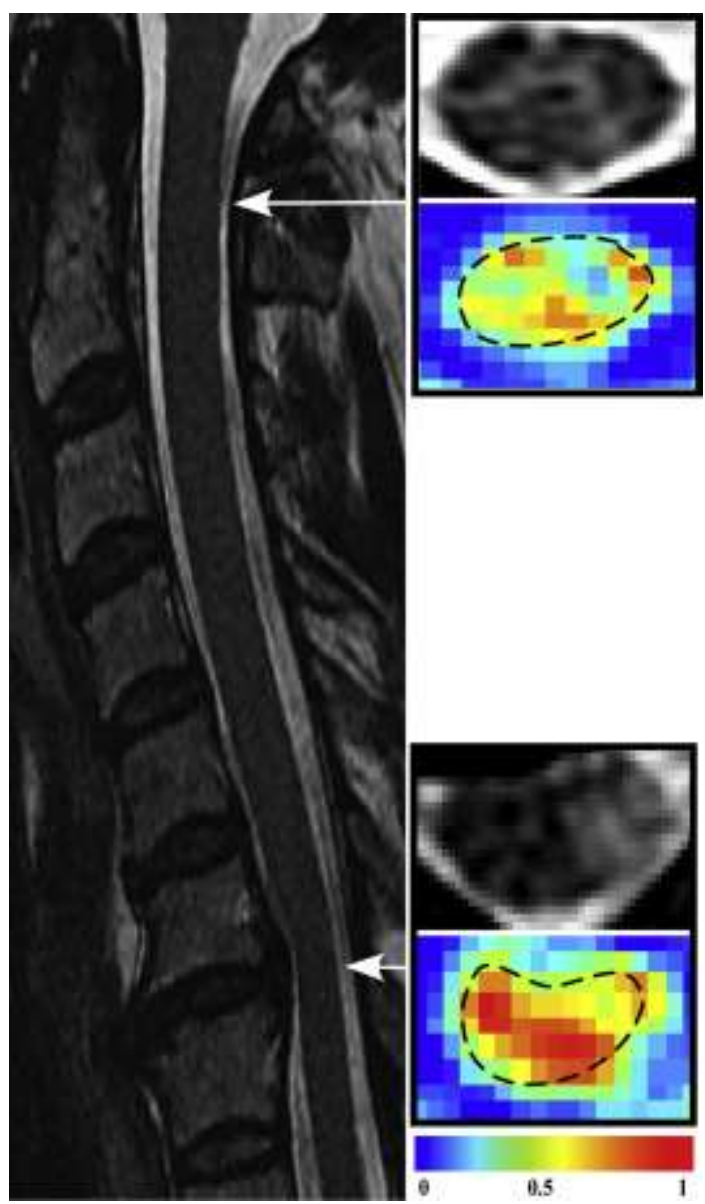

Figure 1. (Left panel) Sagittal T2-weighted magnetic resonance imaging in a 59-yearold woman with cord compression at the C6-7 level and clinical features of cervical myelopathy. (Right panel) Axial T2-weighted images and fractional anisotropy maps at the C1-2 level and C6-7 level show altered cord structure and areas of low anisotropy within the cord. Dashed lines represent regions of interest drawn within the cord to measure fractional anisotropy. 


\section{Statistical Analysis}

We used Pearson correlation to evaluate correlations between DTI metrics and the primary and secondary outcomes as well as the preoperative clinical scores. The level of significance was set as $P<$ 0.05. All data were analyzed using IBM SPSS statistics for Windows 20.0 (IBM Corporation, Armonk, New York, USA).

\section{Results}

For this study, 28 patients with CSM were recruited. Follow-up data at 3 months was available for 27 of 28 patients (96\%), who formed the study group. Demographic and clinical data for the 27 patients with CSM are shown in Table 1 . The mean age was 54.5 years, and most subjects were women $(66 \%)$. Slightly more than half of the subjects reported duration of symptoms of $>12$ months. Patients most often underwent surgery from a posterior approach $(59 \%)$.

Table 1. Demographic and Surgical Characteristics in 27 Patients

\section{Characteristic}

Mean age, years $( \pm S D)$

Male sex

Duration of symptoms $<12$ months

\section{Surgical approach*}

Anterior

Posterior

Anterior + posterior

\section{Value}

$54.5 \pm 1.9$

$12(44 \%)$

$13(48 \%)$

Values are presented as number (\%) except for age.

*All surgical procedures included decompression and fusion. Numbers are rounded and may not add up to 100 .

The most common level of maximum compression was C5-6 (52\%). T2-weighted hyperintensity was noted in $48 \%$ of patients with CSM at the level of maximum compression. The mean FA at the level of maximum compression was $0.5 \pm 0.01$, whereas the mean FA at the C1-2 level was $0.55 \pm 0.01$. The mean FA at the level of maximum compression was significantly lower than the FA at the C1-2 level $(P=$ 0.01). 
At the level of maximum compression, the mean FA was significantly lower in patients with intramedullary T2-weighted signal change compared with patients without this finding (0.46 vs. $0.55, P=$ $0.001)$. At the $\mathrm{C} 1-2$, noncompressed level, there was no significant difference between the 2 groups ( 0.55 vs. $0.56, P=0.57$ ). The preoperative mJOA scale score was significantly lower in patients with intramedullary T2-weighted signal change compared with patients without T2-weighted signal change (12.9 vs. 14.5, $P=0.03$ ).

\section{Clinical Outcome at 3 Months After Surgery}

At 3 months after surgery, mJOA scale scores improved by an average of 0.9 points. Disability as reported on the NDI decreased by an average of 6.0 points, and SF-36 physical functioning subscale score improved by an average of 3.4 points (Table 2 ).

Table 2. Clinical Outcome Scores at 3 Months After Decompressive Surgery for Cervical Spondylotic Myelopathy

\begin{tabular}{lccc} 
Clinical Outcome Measures & Preoperative & Postoperative & \multicolumn{1}{c}{ Change } \\
mJOA scale & $13.7 \pm 0.3$ & $14.7 \pm 0.3$ & $0.9 \pm 0.3$ \\
NDI & $35.1 \pm 3.1$ & $29.0 \pm 2.5$ & $-6.0 \pm 1.9$ \\
SF-36 PF score & $35.0 \pm 2.0$ & $38.5 \pm 2.0$ & $3.4 \pm 1.9$
\end{tabular}

Scores are presented as mean $\pm \mathrm{SE}$.

mJOA, modified Japanese Orthopaedic Association; NDI, Neck Disability Index; SF-36 PF, Short Form-36 physical functioning subscale.

\section{Correlation Between DTI Metrics and Clinical Outcomes at 3 Months in 27 Patients}

FA at the level of maximum cord compression was significantly correlated with change in mJOA scale score at 3 months after surgery (Pearson $r=-0.42, P=0.02$ ) ( Figure 2) but was not significantly correlated with secondary outcomes (NDI, SF-36 physical functioning subscale) (Table 3). FA at C1-2 did not correlate with either the change in mJOA scale score at 3 months $(r=0.13, P=0.51)$ or the change in other secondary outcomes-NDI $(r=0.15, P=0.43)$ and SF-36 physical functioning subscale $(r=-0.16, P=0.4)$.

World Neurosurgery, Vol 97 (January 2017): pg. 489-494. DOI. This article is (C) Elsevier B.V. and permission has been granted for this version to appear in e-Publications@Marquette. Elsevier B.V. does not grant permission for this article to be further copied/distributed or hosted elsewhere without the express permission from Elsevier B.V. 
NOT THE PUBLISHED VERSION; this is the author's final, peer-reviewed manuscript. The published version may be accessed by following the link in the citation at the bottom of the page.

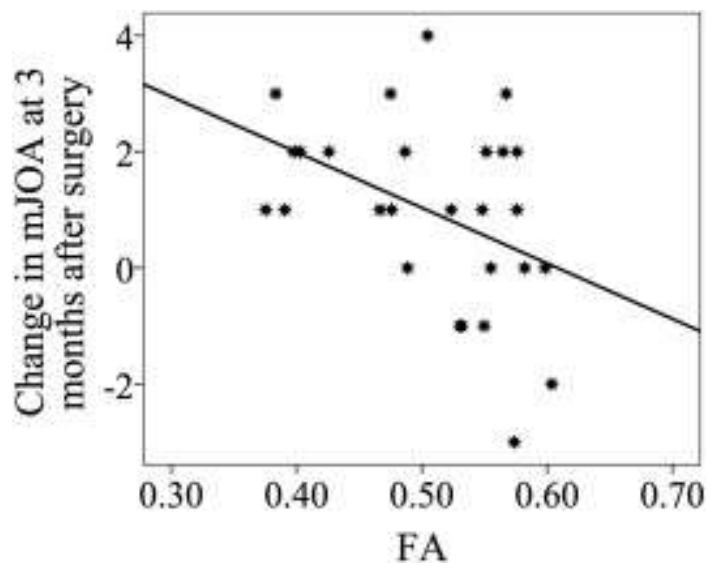

Figure 2. Scatterplot showing correlation between fractional anisotropy (FA) at the level of maximum cord compression and change in modified Japanese Orthopaedic Association (mJOA) scale score at 3 months after decompressive surgery in 27 patients with cervical spondylotic myelopathy.

Table 3. Correlation Between Diffusion Tensor Imaging Fractional Anisotropy at the Level of Maximum Cord Compression and MD with 3-Month Change in Clinical Outcome Scores

\section{Clinical Outcome Measures}

Pearson $r$ FA

$$
\begin{aligned}
& -0.42 \\
& -0.03
\end{aligned}
$$

0.04

SF-36 PF score

FA, fractional anisotropy; MD, mean diffusivity; mJOA, modified Japanese Orthopaedic Association; NDI, Neck Disability Index; SF-36 PF, Short Form-36 physical functioning subscale.

$* P<0.05$.

\section{Correlation Between DTI Metrics and Preoperative Clinical Status in 27 Patients}

FA at the level of maximum cord compression was significantly correlated with the preoperative mJOA scale score (Pearson $r=0.65$, $P<0.001$ ) ( Figure 3) but not with the NDI or SF-36 physical functioning subscale score. FA at C1-2 did not correlate with the preoperative mJOA scale score $(r=-0.16, P=0.4)$.

World Neurosurgery, Vol 97 (January 2017): pg. 489-494. DOI. This article is (C) Elsevier B.V. and permission has been granted for this version to appear in e-Publications@Marquette. Elsevier B.V. does not grant permission for this article to be further copied/distributed or hosted elsewhere without the express permission from Elsevier B.V. 
NOT THE PUBLISHED VERSION; this is the author's final, peer-reviewed manuscript. The published version may be accessed by following the link in the citation at the bottom of the page.

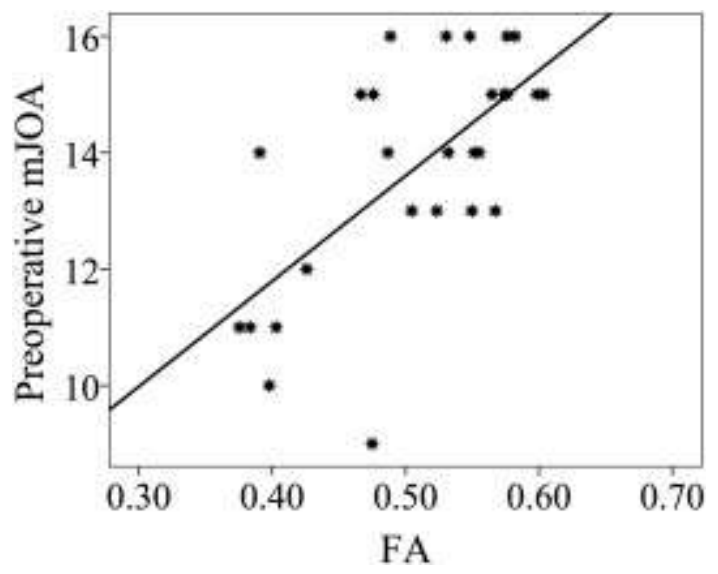

Figure 3. Relationship between fractional anisotropy $(\underline{F A})$ at the level of maximum cord compression and preoperative modified Japanese Orthopaedic Association (mJOA) scale score in 27 patients with cervical spondylotic myelopathy.

\section{Discussion}

The present study demonstrates a significant correlation of $\mathrm{FA}$ with short-term clinical outcome (mJOA scale) after decompressive surgery for CSM. In addition, FA in patients with CSM correlated with preoperative clinical scores, suggesting that FA may be a marker of clinical severity in CSM.

In contrast to conventional MRI, DTI produces quantitative parameters that can be used to predict clinical outcome after decompressive surgery for CSM. Jones et al. $\frac{15}{}$ showed that FA at the level of cord compression was predictive of postoperative NDI at a mean follow-up of approximately 6 months. In the present study, FA at the level of maximum cord compression was correlated with the change in mJOA scale score at 3-month follow-up. Preoperatively, a lower DTI FA was associated with a worse mJOA scale score. At 3 months after surgery, a lower preoperative FA was predictive of a greater improvement in mJOA scale score. Future studies should evaluate the change in DTI parameters after surgical decompression of CSM, as DTI may have utility in predicting neurologic recovery in patients with CSM. To study the predictive value of DTI further, we are also continuing to follow these patients over time.

World Neurosurgery, Vol 97 (January 2017): pg. 489-494. DOI. This article is (C) Elsevier B.V. and permission has been granted for this version to appear in e-Publications@Marquette. Elsevier B.V. does not grant permission for this article to be further copied/distributed or hosted elsewhere without the express permission from Elsevier B.V. 
Cord compression in CSM results in gliosis, demyelination, and axonal injury $\underline{17}$ that disrupt intracellular and intercellular barriers, producing changes in the diffusion of water molecules. These microstructural changes may be the basis for the changes observed in DTI measurements. FA, which is higher in intact, parallel axons, was consistently decreased at the level of cord compression in patients with CSM. $\underline{8}, \underline{11}, \underline{15}, \underline{18}, \underline{19}$ and $\underline{20}$ The lower FA at the level of maximum compression compared with the rostral noncompressed area is indicative of the microstructural changes created by cord compression. Additionally, FA was able to distinguish patients with myelomalacia, as demonstrated by the lower FA values in patients with intramedullary T2-weighted signal change.

NDI, which measures patient disability caused by neck pain, was not significantly correlated with DTI FA; this may be due in part to the design of the survey. The mJOA scale is a disease-specific outcome measure for CSM, and the significant correlation between FA and mJOA scale score suggests that FA may be a better marker for myelopathy than neck pain and disability related to neck pain.

Our findings suggest that DTI of the cervical spinal cord is a potential biomarker for spinal cord dysfunction in patients with CSM. Similar to Jones et al.,$\underline{15}$ we found that the FA at the level of cord compression was associated with the preoperative mJOA scale score. Budzik et al. $\underline{11}$ showed that the FA at the level of maximum cord compression correlated with upper and lower limb function as measured by the Japanese Orthopaedic Association Cervical Myelopathy Evaluation Questionnaire. These findings indicate that DTI may provide information to supplement conventional MRI findings in CSM. Also, FA could probably define structure-function relationships in patients with CSM, as has been described in patients with spinal cord injury. ${ }^{21}$ Future studies will investigate the association between cervical cord DTI metrics and neurophysiologic function in patients with CSM.

This study is limited by a small number of patients evaluated in a single tertiary care academic center. Although this study focuses on short-term clinical outcomes, it adds to the limited prospective data available on the predictive value of DTI for surgical outcomes in cervical spondylotic myelopathy. With longer follow-up, we are likely to

World Neurosurgery, Vol 97 (January 2017): pg. 489-494. DOI. This article is (C) Elsevier B.V. and permission has been granted for this version to appear in e-Publications@Marquette. Elsevier B.V. does not grant permission for this article to be further copied/distributed or hosted elsewhere without the express permission from Elsevier B.V. 
see further improvements in the clinical and functional scores, and it is possible that we could find stronger clinical correlates for DTI metrics. Our evaluation of patients with mild myelopathy may have been affected by small changes in mJOA scale scores as a result of the ceiling effect $\underline{22}$ as well as the limited sensitivity of the mJOA scale in milder levels of myelopathy. $\underline{23}$ Most patients ( $81 \%)$ in this study had mJOA scale scores $\geq 12$. Future studies could perform subgroup analysis based on the severity of myelopathy and possibly the presence of T2-weighted hyperintensity. A larger sample size would allow better analysis of the relationship between DTI indexes and outcome, taking into account patient characteristics and surgical approach. Although FA was sensitive to cord damage in patients with mild to moderate CSM, future studies would benefit from including patients with CSM who had more severe myelopathy. Performing DTI of the spinal cord postoperatively remains a challenge in patients with CSM because spinal instrumentation produces considerable artifacts within the diffusion images. One mechanism to overcome this difficulty would be to determine whether DTI indexes in the high cervical spinal cord ( $\mathrm{C} 1-2)$ reflect the microstructural alterations at the level of maximum stenosis, as seems to be the case in patients with spinal cord injury. ${ }^{24}$ Although there is a need for long-term follow-up data and studies with larger sample sizes, the present study provides a preliminary insight into the possibility of using DTI as a noninvasive biomarker to predict postoperative outcomes. We believe this study will add to the limited literature available on this topic, and we encourage surgeons to further evaluate this technique.

\section{Conclusions}

DTI FA measured before surgery was significantly correlated with the 3-month change in mJOA scale score among patients with CSM. DTI FA was also significantly associated with preoperative mJOA scale score and is a potential biomarker for spinal cord dysfunction in patients with CSM.

\section{References}

${ }^{1}$ C.J. Chen, R.K. Lyu, S.T. Lee, Y.C. Wong, L.J. Wang. Intramedullary high signal intensity on T2-weighted MR images in cervical spondylotic

World Neurosurgery, Vol 97 (January 2017): pg. 489-494. DOI. This article is (C) Elsevier B.V. and permission has been granted for this version to appear in e-Publications@Marquette. Elsevier B.V. does not grant permission for this article to be further copied/distributed or hosted elsewhere without the express permission from Elsevier B.V. 
NOT THE PUBLISHED VERSION; this is the author's final, peer-reviewed manuscript. The published version may be accessed by following the link in the citation at the bottom of the page.

myelopathy: prediction of prognosis with type of intensity. Radiology, 221 (2001), pp. 789-794

2 Y. Morio, K. Yamamoto, K. Kuranobu, M. Murata, K. Tuda. Does increased signal intensity of the spinal cord on MR images due to cervical myelopathy predict prognosis? Arch Orthop Trauma Surg, 113 (1994), pp. 254-259

3 K. Yone, T. Sakou, M. Yanase, K. Ijiri. Preoperative and postoperative magnetic resonance image evaluations of the spinal cord in cervical myelopathy. Spine (Phila Pa 1976), 17 (1992), pp. S388-392

4 Y. Morio, R. Teshima, H. Nagashima, K. Nawata, D. Yamasaki, Y. Nanjo. Correlation between operative outcomes of cervical compression myelopathy and MRI of the spinal cord. Spine (Phila Pa 1976), 26 (2001), pp. 1238-1245

5].J. Shin, B.H. Jin, K.S. Kim, Y.E. Cho, W.H. Cho. Intramedullary high signal intensity and neurological status as prognostic factors in cervical spondylotic myelopathy. Acta Neurochir (Wien), 152 (2010), pp. 1687-1694

${ }^{6}$ A. Vedantam, A. Jonathan, V. Rajshekhar. Association of magnetic resonance imaging signal changes and outcome prediction after surgery for cervical spondylotic myelopathy. J Neurosurg Spine, 15 (2011), pp. 660-666

IE. Wada, K. Yonenobu, S. Suzuki, A. Kanazawa, T. Ochi. Can intramedullary signal change on magnetic resonance imaging predict surgical outcome in cervical spondylotic myelopathy? Spine (Phila Pa 1976), 24 (1999), pp. 455-456

${ }^{8}$ B. Kara, A. Celik, S. Karadereler, L. Ulusoy, K. Ganiyusufoglu, L. Onat, et al. The role of DTI in early detection of cervical spondylotic myelopathy: a preliminary study with 3-T MRI. Neuroradiology, 53 (2011), pp. 609616

${ }^{9}$ T. Song, W.J. Chen, B. Yang, H.P. Zhao, J.W. Huang, M.J. Cai, et al. Diffusion tensor imaging in the cervical spinal cord. Eur Spine J, 20 (2011), pp. 422-428

10p.J. Basser, C. Pierpaoli. Microstructural and physiological features of tissues elucidated by quantitative-diffusion-tensor MRI. J Magn Reson B, 111 (1996), pp. 209-219

11].F. Budzik, V. Balbi, V. Le Thuc, A. Duhamel, R. Assaker, A. Cotton. Diffusion tensor imaging and fibre tracking in cervical spondylotic myelopathy. Eur Radiol, 21 (2011), pp. 426-433

${ }^{12}$ A. Demir, M. Ries, C.T. Moonen, J.M. Vital, J. Dehais, P. Arne, et al. Diffusion-weighted MR imaging with apparent diffusion coefficient and apparent diffusion tensor maps in cervical spondylotic myelopathy. Radiology, 229 (2003), pp. 37-43

World Neurosurgery, Vol 97 (January 2017): pg. 489-494. DOI. This article is (C) Elsevier B.V. and permission has been granted for this version to appear in e-Publications@Marquette. Elsevier B.V. does not grant permission for this article to be further copied/distributed or hosted elsewhere without the express permission from Elsevier B.V. 
NOT THE PUBLISHED VERSION; this is the author's final, peer-reviewed manuscript. The published version may be accessed by following the link in the citation at the bottom of the page.

133. Hori, T. Okubo, S. Aoki, H. Kumagai, T. Araki. Line scan diffusion tensor MRI at low magnetic field strength: feasibility study of cervical spondylotic myelopathy in an early clinical stage. J Magn Reson Imaging, 23 (2006), pp. 183-188

${ }^{14} \mathrm{H}$. Mamata, F.A. Jolesz, S.E. Maier. Apparent diffusion coefficient and fractional anisotropy in spinal cord: age and cervical spondylosisrelated changes. J Magn Reson Imaging, 22 (2005), pp. 38-43

15].G. Jones, S.Y. Cen, R.M. Lebel, P.C. Hsieh, M. Law. Diffusion tensor imaging correlates with the clinical assessment of disease severity in cervical spondylotic myelopathy and predicts outcome following surgery. AJNR Am J Neuroradiol, 34 (2013), pp. 471-478

${ }^{16}$ C. Pierpaoli, P.J. Basser. Toward a quantitative assessment of diffusion anisotropy. Magn Reson Med, 36 (1996), pp. 893-906

17K. Ono, H. Ota, K. Tada, T. Yamamoto. Cervical myelopathy secondary to multiple spondylotic protrusions: a clinicopathologic study. Spine (Phila Pa 1976), 2 (1977), p. 109

18 M. Kerkovsky, J. Bednarik, L. Dusek, A. Sprlakova-Pukova, I. Urbanek, M. Mechl, et al. Magnetic resonance diffusion tensor imaging in patients with cervical spondylotic spinal cord compression: correlations between clinical and electrophysiological findings. Spine (Phila Pa 1976), 37 (2012), pp. 48-56

19].W. Lee, J.H. Kim, J.B. Park, K.W. Park, J.S. Yeom, G.Y. Lee, et al. Diffusion tensor imaging and fiber tractography in cervical compressive myelopathy: preliminary results. Skeletal Radiol, 40 (2011), pp. 15431551

${ }^{20} \mathrm{~T}$. Uda, T. Takami, N. Tsuyuguchi, S. Sakamoto, T. Yamagata, H. Ikeda, et al. Assessment of cervical spondylotic myelopathy using diffusion tensor magnetic resonance imaging parameter at 3.0 tesla. Spine (Phila Pa 1976), 38 (2013), pp. 392-400

211P. Freund, T. Schneider, Z. Nagy, C. Hutton, N. Weiskopf, K. Friston, et al. Degeneration of the injured cervical cord is associated with remote changes in corticospinal tract integrity and upper limb impairment. PLoS One, 7 (2012), p. e51729

$\underline{22}$ A. Karpova, R. Arun, A.M. Davis, A.V. Kulkarni, E.M. Massicotte, D.J. Mikulis, et al. Predictors of surgical outcome in cervical spondylotic myelopathy. Spine (Phila Pa 1976), 38 (2013), pp. 392-400

$\underline{23}$ A. Singh, H.A. Crockard. Comparison of seven different scales used to quantify severity of cervical spondylotic myelopathy and postoperative improvement. J Outcome Meas, 5 (2001), pp. 798-818

${ }^{24}$ A. Vedantam, G. Eckardt, M.C. Wang, B.D. Schmit, S.N. Kurpad. Clinical correlates of high cervical fractional anisotropy in acute cervical spinal cord injury. World Neurosurg, 83 (2015), pp. 824-828

World Neurosurgery, Vol 97 (January 2017): pg. 489-494. DOI. This article is (C) Elsevier B.V. and permission has been granted for this version to appear in e-Publications@Marquette. Elsevier B.V. does not grant permission for this article to be further copied/distributed or hosted elsewhere without the express permission from Elsevier B.V. 
NOT THE PUBLISHED VERSION; this is the author's final, peer-reviewed manuscript. The published version may be accessed by following the link in the citation at the bottom of the page.

Conflict of interest statement: Funding for this study was provided by the Robert Wood Johnson Foundation and Department of Veterans Affairs Rehabilitation Research and Development Grant Number 1 I01 RX000113-01.

To whom correspondence should be addressed: Shekar N. Kurpad, M.D., Ph.D. 